\title{
Two modes of learning-oriented leadership: a study of first-line managers
}

Eva Ellström and Per-Erik Ellström

The self-archived postprint version of this journal article is available at Linköping University Institutional Repository (DiVA):

http:// urn.kb.se/ resolve?urn=urn:nbn:se:liu:diva-152671

N.B.: When citing this work, cite the original publication.

Ellström, E., Ellström, P., (2018), Two modes of learning-oriented leadership: a study of first-line managers, J ournal of Workplace Learning, 30(7), 545-561. https:// doi.org/ 10.1108/J WL-03-20180056

Original publication available at:

https:/ / doi.org/ 10.1108/JWL-03-2018-0056

Copyright: Emerald

http:// www.emeraldinsight.com/ 


\title{
Two modes of learning-oriented leadership: A study of first-line managers
}

\author{
Eva Ellström \\ Per-Erik Ellström \\ HELIX Competence Centre \\ Department of Behavioural Sciences and Learning \\ Linköping University \\ SE-581 83 Linköping, Sweden
}

Corresponding author: Eva Ellström can be contacted at: eva.ellstrom@liu.se 


\begin{abstract}
Purpose - The purpose of this study was to explore what learning-oriented leadership could mean in practice and to identify possible sources of variability in this leadership between firstline managers (FLMs). The empirical basis of the study comprised FLMs in nursing homes for elderly care.
\end{abstract}

Design/methodology/approach - The study was carried out using a sequential mixedmethod design with interviews, observations and documentary analysis.

Findings - The study contributes an in-depth analysis of two modes of learning-oriented leadership: development-oriented and production-oriented. The two orientations represent an open and enabling pattern versus a constraining and controlling pattern of leading and organizing employee learning and development. The observed differences in learningoriented leadership between the FLMs were interpreted in terms of the demands-constraintschoices model proposed by Stewart (1982; 1989).

Research limitations/implications - Future research should study the effects of the two modes of learning-oriented leadership on employees’ informal learning at work, and also on learning outcomes and transfer from formal training and development efforts.

Practical implications - It is important that employee learning and development issues are clearly linked to business strategies, and that senior managers actively support and follow up on FLMs' work with these issues. Furthermore, there is a strong need for training and development of FLMs - formal and informal - to improve their knowledge of and skills in leading and organizing workplace learning.

Originality/value - The study adds to previous research by elaborating what learningoriented leadership could mean in practice and how it can be theoretically understood. Key-words Learning-oriented leadership, learning, managerial work, first-line managers Paper type Research paper 


\section{Two modes of learning-oriented leadership:}

\section{A study of first-line managers}

\section{Introduction}

The focus of the present study concerns the role of line managers, particularly first-line managers (FLMs), in leading and organizing employees’ learning and competence development at work. The importance of this topic is argued in research on workplace learning (e.g., Coetzer, 2007; Poell and van Woerkom, 2011) as well as in research on the devolution of human resource (HR) responsibilities to line managers and what this means for the role of FLMs (Cunningham and Hyman, 1999; Whittaker and Marchington, 2003).

A common theme of these two strands of research is the potentially important role of FLMs in facilitating employee learning and development and an envisioned shift away from their role as subject-matter experts and controllers towards a more educative and supportive role (Ellinger, Watkins and Barnas, 1999; Hamlin, Ellinger and Beattie, 2006). Studies have described this allegedly new management role in terms of coaching (Hamlin et al., 2006), knowledge leadership (Viitala, 2004), or learning-oriented leadership (Döös, Johansson and Wilhelmson, 2015; Wallo, 2008; 2017). This latter term will be used in this article.

Although the ideas of a new management role have gained widespread acceptance as a normative ideal, an examination of empirical research reveals a more complex and partly contradictory picture. On the one hand, a number of studies show that the role of first-line managers has indeed changed towards increasing responsibilities for HR-issues, including training and facilitation of employee learning at work (e.g. Cunningham and Hyman, 1999; Whittaker and Marchington, 2003; Hutchington \& Purcell, 2010). On the other hand, empirical research also indicates that the compliance to this ideal in everyday practice has been modest and that line managers' responses are mixed or even negative (Ellinger et al., 2011; Ellström E., 2012; Hutchington and Purcell, 2007). There is also evidence that 
performance-oriented supervision is still at the core of the FLM role and that actual role changes over time are limited (e.g., Hales, 2005; Hales, 2006/2007). Given these seemingly contradictory findings, the purpose of this study was to explore what learning-oriented leadership could mean in practice and to identify possible sources of variability in this leadership between FLMs.

The empirical basis of the study comprised FLMs in nursing homes for elderly care. Elderly care is presently facing a number of challenges related to, among other things, a growing number of elderly in need of advanced health care, and a more complex and sophisticated knowledge-base due to medical and technological advances (e.g. Hasson \& Arnetz, 2008). These and other factors put increasing demands on the competence of staff as well as managers. In spite of this, opportunities for formal training are limited and changing competence requirements are largely to be met through informal learning at work (Ekholm, 2012; Furåker \& Nilsson, 2010). This of course highlights the importance of the workplace as a learning environment and the role of the FLMs for promoting learning and development of the nursing staff (The National Board of Health and Welfare, 2011).

\section{Conceptual Framework and Related Research}

\subsection{The notion of learning-oriented leadership}

Following Mintzberg (2009), we view leadership as one of several managerial roles that, among other things, includes encouraging and supporting people to do their work more effectively as well as supporting their development (e.g., through coaching or training). Considering learning-oriented leadership more specifically, this notion refers to managerial work with a more or less conscious focus on the educative task to promote employee learning and competence development at work. In terms of Mintzberg (2009), this would mean a shift towards managing through people rather than through information or direct action. 
The interest in the notion of learning-oriented leadership in recent years can be seen as a response to the increasing focus on the workplace as a site not only for production of goods or services but also for learning (Ellström, 2001; Malloch et al., 2011). In this perspective, it is reasonable to ask what it takes to organize and lead for both production and learning, and, thus, what a learning-oriented leadership would mean? As will be argued in the next section, the answer partly depends on what we mean by learning in this context. However, the answer also depends on how tensions and trade-offs between the demands of production and those of learning are viewed and handled by the organization. Tensions for example concerning the degree of employee discretion (autonomy) in and over the work that is allowed by the organization and the forms of control that are used. These aspects of learning-oriented leadership are aptly captured by Dirkx (1999) in his discussion of the tensions between a managerial interest "to get workers to where they want them to be" contrary to "a desire to encourage them to be reflective about their work” (p. 133).

Two further comments should be made concerning the meaning of learning-oriented leadership as used here. First, in line with Döös et al. (2015), we do not restrict learningoriented leadership to face-to-face interactions with people (i.e., direct leadership); we also include leadership that involves no direct interaction (i.e., indirect leadership). Examples of indirect leadership include leader influence through development programmes, management systems, or different types of structural arrangements (e.g., teamwork; Yukl, 2013). Second, in contrast to the many studies that focus on leadership in terms of leadership behaviours or styles detached from an organizational context (Yukl, 2009), the present study concerns managers' views, practices and interactions in the context of actual workplaces.

\subsection{Two logics of leadership and learning}

As conceptual tools for describing and analysing learning-oriented leadership, we distinguish between two logics of leadership and learning: the logic of development and the logic of 
production (Ellström, 2006; 2010; 2011). These two logics are defined in terms of two forms of learning: developmental learning and adaptive learning (Ellström, 2001; 2011).

The logic of production focuses on the mastery of given tasks, situations or methods and on efficient, reliable and stable task performance (cf. the notion of exploitation as discussed by March, 1991). Thus, this logic entails adaptive learning - for example, learning a particular way of working in accordance with prescribed routines in an organization, or learning to improve task performance (Ellström, 2001). To promote adaptive learning, the logic of production emphasizes reduction in performance variation through, for example, standardization of work processes. In terms of the typology of leadership practices (interventions) proposed by Döös et al. (2015), learning-oriented leadership consistent with this logic focuses on narrowing employees' discretion in performing their work.

In contrast, the logic of development entails developmental (creative) learning and thereby preparedness to reflect upon and question the tasks at hand (“are we doing the right things?”), and, if necessary, to change established practices into new solutions or ways of working (Ellström, 2001; cf. the notion of exploration, March, 1991). One way to promote developmental learning is to create conditions for openness, variation and diversity in thought and action within the organization by adopting leadership practices (interventions) that aim to widen rather than narrow employee discretion at work (cf. Döös et al., 2015).

In summary, the two logics are understood here as two ideal-typical patterns of managerial practice and leadership that both entail learning as a basic mechanism for promoting efficient performance (in the one case) and innovativeness (in the other case). One pattern or the other is assumed to predominate for a given manager due to individual and/or contextual factors.

\subsection{Related Research}

With the purpose of the study in mind, the analysis of previous research was structured in 
terms of two questions: What does it mean to exercise a learning-oriented leadership, and why do managers differ in their way of exercising such a leadership?

Starting with the what-question, a number of previous studies have been able to empirically identify different patterns of learning-oriented leadership among line managers. Based on a review of case studies, McGill et al. (1992) distinguished between two types of managerial practice: one promoting adaptive learning the other generative learning. While the former was characterized by a controlling perspective and a narrow problem-solving orientation, the latter was characterized by openness and systemic thinking.

Ellinger (2005) identified leadership behaviours that were viewed to positively or negatively influence informal learning at work. Leadership that created learning opportunities, encouraged risk taking, supported and made space for learning were viewed as having a positive influence, while managers that were not committed to learning, and that exhibited an authoritarian approach to leadership (“telling people what to do”) were viewed as having a negative influence on employee learning. These findings were largely validated by a later study (Ellinger, Hamlin and Beattie, 2008), where a number of “ineffective management behaviours” associated with command, control, compliance and coercive styles of management were contrasted with a "coaching management paradigm” with a focus on encouraging empowerment, inclusion, and participation.

Based on studies of FLMs in manufacturing companies, Wallo (2008; 2017) and Wallo, Ellström and Kock (2013) distinguished between performance-oriented and developmentoriented leadership. The former type focused mainly on improving employees’ performance through adaptive learning and building on their current knowledge; this was the predominating orientation in both studies. However, there was also evidence of developmentoriented leadership, which aimed to expand employees’ current knowledge and to foster innovative learning and problem-solving in daily work. In line with these findings, Ellström, 
E. (2012) in a study of FLMs in elderly care identified two orientations - a constraining orientation and an enabling orientation - of managerial support for employee learning at work. The former orientation was characterized by a focus on daily operations and administration and little or no focus on employee learning and development. The latter was characterized by a dialogue-based pattern of work and a focus on the facilitation of employee reflection on various work-related issues.

In summary, the findings from these studies point to a dual nature of learning-oriented leadership: one the one hand a controlling and constraining orientation, on the other hand a supporting and enabling orientation. These results are thus largely consistent with the distinction between the logic of production and the logic of development proposed above as a framework for analysing learning-oriented leadership.

Turning now to the why-question, we may distinguish at least two lines of argumentation concerning how to explain differences in learning-oriented leadership. On the one hand, arguments to the effect that contextual factors, for example, work overload, managerial shorttermism, role conflicts and/or pressures from administrative and business duties, constrain and influence the extent and how line managers engage in a learning-oriented leadership (e.g. Cunningham \& Hyman, 1999; Hutchington \& Purcell, 2007; 2010; Whittaker \& Marchington, 2003; Wallo et al., 2013).

On the other hand, arguments with a more voluntaristic orientation (e.g. Hutchington \& Purcell, 2007; 2010; McGovern et al, 1997). These latter arguments suggest that managers have considerable discretion - within certain constrains and demands - and that performance of HR tasks is to a large extent a matter of priorities and choices (cf. Stewart, 1982). Of course, then the question arises how to explain the actual choices that managers do in a certain context? In addition to the different types of contextual factors mentioned above, several studies argue for the importance of subjective factors; primarily, the managers' 
interest in and understanding of their tasks as managers, and their ability (competence) to effectively perform the different tasks that are expected to be part of the job (e.g. Bos-Nehles et al., 2013; Carroll and Gillen, 2002; Ellström E., 2012; Hutchington and Purcell, 2007). However, as argued by Wallo et al. (2013), these and other factors may in turn be influenced not least by the collective understanding of the role of leadership in the local context, that is, by factors in the organizational culture.

\section{The Present Study}

Although previous studies provide valuable knowledge, there is still a paucity of theorybased, empirical research on how line managers understand and deal with learning and developmental issues in the workplace. If we consider the field of care work, and elderly care in particular, our knowledge about these issues is even more limited.

This study adds to previous research by an empirically grounded analysis of what learning-oriented leadership might mean in practice, how it can be theoretically understood and under what conditions FLMs are likely to engage in different forms of learning-oriented leadership. The study was informed by theory and research on learning at work and organizational learning (e.g. Ellström, 2001; 2011; Malloch et al., 2011; March, 1991).

As was noted in the introduction, the empirical basis of the study comprised FLMs in nursing homes for elderly care. The role of these FLMs comprises a broad range of management responsibilities (Ekholm, 2012; Furåker \& Nilsson, 2010), including supervision of nursing staff, budget matters, work environment, quality management, competence development and other HR issues. The responsibilities for competence development include supporting and coaching the nursing staff in their daily work (The National Board of Health and Welfare, 2011).

Against this background, the following three research questions were addressed: 
RQ1. What characterized the ways in which the FLMs included in this study viewed and handled employee learning and competence development - that is, what characterized their learning-oriented leadership?

RQ2. To what extent was the FLMs' learning-oriented leadership related to (a) individual background characteristics and (b) organizational characteristics, specifically, ownership of operations (i.e., public or private) and management responsibilities (e.g., number of employees/span of control)?

RQ3. To what extent was the FLMs' learning-oriented leadership related to explicit demands, expectations or support from senior managers?

\section{Methods}

\subsection{Setting and Participants}

The study was carried out in a mid-sized Swedish municipality. Although elderly care is publicly funded through taxes, many municipalities have privatized parts of their elderly care. In the present study sample, private operators run nearly two-thirds of the nursing homes. The number of employees at the nursing homes ranged between 20 to 70, with a mean of 41 employees. The staff comprised mainly licensed practical nurses. In addition, each nursing home included one or two registered nurses. Most of the employees (94 percent) were women.

With regard to organizational structure, the FLMs occupied a middle-management position between the staff and a senior manager to whom they reported. The latter was responsible for the elderly care operations within the municipality or within the private company that ran the unit. When this study was carried out, five private and one public care provider had contracts with the municipality for provision of elderly care.

After informed consent was obtained, the first step of data collection included all 32 FLMs who were responsible for a nursing home in the municipality. The FLMs were mostly 
women (29 persons or 91 percent) who had worked as managers for, on average, more than 10 years $(M=14)$ and had a mean age of 49 years. Most of the FLMs (30 out of 32) had an academic degree in social work $(n=15)$, nursing or paramedics $(n=12)$, behavioural sciences or human resources $(\mathrm{HR})(\mathrm{n}=3)$. In addition to their basic professional education, some of the FLMs ( $\mathrm{n}=7$ ) had further education/training in HR, communication or leadership development.

\subsection{Data Collection and Analysis}

The study was carried out using a sequential mixed method design (Tashakkori \& Teddlie, 2003) based on individual interviews, observations and documentary analysis. This mixedmethods approach allowed for an analysis from different perspectives and for methodological triangulation. The sequential character of the study was also helpful for successively focusing on subsequent data collection. The data collection and analysis were carried out in three different but related steps.

\subsubsection{Step 1}

In the first step, semi-structured telephone interviews (Novick, 2008) were carried out with all 32 FLMs and the senior managers $(n=6)$.

Interviews with FLMs and senior managers. In addition to individual and organizational characteristics, the interviews with the FLMs focused on the following three main areas: the FLMs' views of their work, priorities and working conditions; the FLMs' views of and ways of working with employee learning and competence development; and the forms and content of formal and informal meetings and how the FLMs viewed their own tasks and role in different types of meetings. The interviews with the senior managers focused on their expectations and demands of the FLMs; their views of the FLMs' ways of working with employee learning and competence development; and their contact with FLMs, their support of and follow-up on the FLMs' work. The interviews with the FLMs and the senior managers 
lasted between 60 and 80 minutes. All interviews were tape-recorded and transcribed verbatim.

Qualitative analysis. The interviews were read several times by both researchers for a holistic view of each interview. Going back and forth between our guiding concepts, relevant previous research and interview data, we were able to identify two main categories (patterns): a development-oriented and a production-oriented mode of learning-oriented leadership. Although we analysed the data with "theory in mind", inspired by an adaptive theory approach (Layder, 1998), we were mindful to be open and sensitive to the empirical material. In the process of creating the two main categories, we successively identified four dimensions (aspects) that could define the meaning of the two main categories (see Table 1). Our rationale for defining and describing the two main categories in terms of these four dimensions, was that they, taken together, provided reasonable meaning and internal consistency to the two main categories and that they simultaneously differentiated between them in a meaningful way (cf. Patton, 1990).

\subsubsection{Step 2}

In a second step, we conducted a follow-up study of a sub-sample of nine FLMs. The main purpose of the follow-up study was to pursue a deeper understanding of the findings from the first step and to gain a more holistic picture of the FLMs' daily work, their relations to and communication with employees, and their ways of handling different situations. It also allowed us to take contextual features of the FLMs' work into account. A further purpose of the follow-up study was to validate the findings from the telephone interviews.

The follow-up study included observations (“shadowing”, Czarniawska, 2007)of informal interactions and formal meetings over two days. The observations focused on the daily working practices and activities of the FLMs, including their communication and interactions with employees, and were documented through field notes, which were later transcribed. At 
the end of the second day, we carried out in-depth contextual interviews that covered the main areas in the previous interviews related to the events and interactions that we had observed over the two days.

The follow-up study was carried out about one and a half years after the first interviews. At this point in time, only 14 of the original 32 FLMs remained in their positions and could be considered for inclusion in the follow-up study. The participants in the follow-up study were selected through purposeful, theory-driven sampling (Miles and Huberman, 1994; Patton, 1990) on the basis of the telephone interviews. This resulted in a sample comprising four FLMs categorized as development-oriented and five categorized as production-oriented.

\subsubsection{Step 3}

Addressing the second research question (RQ2), the total sample of 32 FLMs was divided into two subsamples corresponding to the two main categories of learning-oriented leadership. To accomplish this, all telephone interviews were re-read several times by both researchers, and when possible, the information was systematically related and compared with available data from the observations and contextual interviews that were carried out in Step 2. This process continued until we reached an agreement concerning how to classify each of the managers. In this process, it became clear that the interviews with two of the FLMs were too vague and superficial in important respects, and we were unable to decide whether they should be classified as development- or production-oriented. Therefore, we excluded these two FLMs from the further analysis, which was then based on 30 FLMs.

In the analysis to address RQ2, we performed comparisons between the two groups of FLMs (i.e., development- and production-oriented learning leadership). We used Fisher’s exact probability test to compare the qualitative variables (e.g., gender and education) and ttests to compare the means (e.g., age). 


\section{Findings}

The results of the study are presented below in three sections relating to the three research questions.

\subsection{Two modes of learning-oriented leadership (RQ1)}

The formal role and responsibilities of the FLMs were similar across the six elderly care organizations. However, despite the overall similarities in work content, we identified two different patterns concerning how the managers viewed and, in practice, handled issues concerning employee learning and competence development. These patterns, called the development-oriented and production-oriented modes of learning-oriented leadership, are described and differentiated below in terms of the following four dimensions:

(1) Overall orientation of FLMs’ work

(2) Learning orientation

(3) Leading and organizing learning and competence development

(4) Follow-up on competence development

A summary of the two patterns of learning-oriented leadership is presented in Table 1.

\subsubsection{Development-oriented mode of leadership}

Overall orientation. All development-oriented FLMs focused on the development of both employees and operations. As expressed by one manager:

It is exciting to test new ways of working and to be one step ahead of other units....in order to deliver something good. We are required to be result-oriented, but development and results are connected (DO4). To be able to work actively with development issues, most of these FLMs emphasized that they needed to prioritize and delegate in order to avoid "drowning” in administration and "to create time” for work with development:

It is important to have a clear structure and planning when it comes to administration in order to create time for being at hand for the employees. I prioritize encouraging and supporting the employees because they are doing the real job with the elderly (DO8). 
In line with this statement and similar ones, the development-oriented managers typically were closely involved in daily operations, interacting directly with the employees to be able to catch up on everyday worries and jointly find solutions. They also expressed great interest in working with developmental issues.

Table 1. Two modes of learning-oriented leadership

\begin{tabular}{|c|c|c|}
\hline Dimension: & $\begin{array}{l}\text { Development-oriented } \\
\text { leadership }\end{array}$ & $\begin{array}{l}\text { Production-oriented } \\
\text { leadership }\end{array}$ \\
\hline $\begin{array}{l}\text { Overall orientation } \\
\text { of the FLM's work }\end{array}$ & $\begin{array}{l}\text { - Development issues related to } \\
\text { employees and operations } \\
\text { - Use of time for direct interaction } \\
\text { with employees }\end{array}$ & $\begin{array}{l}\text { - Administrative issues and } \\
\text { performance indicators } \\
\text { - Limited use of time for direct } \\
\text { interaction with employees }\end{array}$ \\
\hline Learning orientation & - Developmental learning & - Adaptive learning \\
\hline $\begin{array}{l}\text { Leading and organizing } \\
\text { learning and competence } \\
\text { development }\end{array}$ & $\begin{array}{l}\text { - Use of a broad range of educational } \\
\text { interventions } \\
\text { - Focus on learning through daily } \\
\text { work } \\
\text { - A participatory and dialogue- } \\
\text { oriented pattern of leadership }\end{array}$ & $\begin{array}{l}\text { - Use of formal training } \\
\text { courses as the primary means } \\
\text { for competence development } \\
\text { - Little or no focus on learning } \\
\text { through daily work } \\
\text { - A directive and instruction- } \\
\text { oriented pattern of leadership }\end{array}$ \\
\hline $\begin{array}{l}\text { Follow-up on competence } \\
\text { development }\end{array}$ & $\begin{array}{l}\text { - Systematic follow-up on } \\
\text { competence development } \\
\text { - Support and facilitation of } \\
\text { knowledge use in daily work. }\end{array}$ & $\begin{array}{l}\text { - Limited or no systematic } \\
\text { follow-up on competence } \\
\text { development } \\
\text { - Little or no support of } \\
\text { knowledge use in daily work }\end{array}$ \\
\hline
\end{tabular}

Learning orientation. The development-oriented managers expressed a strong emphasis on employee "growth” and participation in joint problem-solving activities during day-to-day work as well as in formal meetings, and, in some cases, in specific projects (e.g., work with continuous improvements):

Our focus is to provide good and safe care and at the same time support and challenge the employees in a way that enables them to grow (DO1).

As inferred from the data, the managers in this category had a clear orientation towards developmental learning. This was evident, for example, from the managers' use of meetings 
and situations in day-to-day work as occasions for promoting reflection among the staff and a questioning attitude concerning established routines and ways of working:

The tacit knowledge of the employees is articulated and made visible through reflection during team meetings as well as in everyday work situations (DO1).

.... although the staff is very competent, they are also to a large extent routinized. ... it then becomes difficult on many occasions to think outside the box. Nothing happens when everybody thinks in the same way. Therefore, it is important to test new ways of working and then follow up on these changes (DO5).

In line with this, the above-quoted manager (DO5), who was relatively new as a manager in this unit, concluded that "we are on our way" towards changing a prevailing old "assembly line culture” in the employees' way of thinking and working.

Leading and organizing learning and competence development. All of the developmentoriented FLMs expressed that the learning and competence development of the employees was a central and important part of their managerial role:

Working with competence development is a part of my job as a manager and indeed a cornerstone of the job ....... As a manager, I have the responsibility to organize in different ways for the continuous development of the operations and for increasing the skill level of the employees (DO7).

Although the managers had access to a relatively rich supply of education and training through different courses, including web-based courses, all of the development-oriented FLMs emphasized learning in everyday work as an important, or even the most important, approach to the competence development of their staff:

The most important competence development happens in everyday work, here and now. .... through reflection and discussion, for example, at coffee breaks and meetings. We always discuss what we do and why we do it in a certain way (DO3).

In line with this, the development-oriented FLMs used a broad range of learning activities, including problem solving during meetings or in everyday work situations, implementing continuous improvements, testing and following up on new ways of working, giving feedback to individual employees, and delegating responsibilities: 
I use team meetings for problem solving and reflection. It is important to discuss why you are doing things one way or the other. And to get opportunities to reflect on why we are here, how we work and should work with different tasks (DO9).

Several of the development-oriented FLMs described their ways of working with employee learning and competence development in terms of "coaching”. The data also indicated that in many situations - both individually in everyday work situations and in group settings during meetings - these managers used a participatory and dialogue-based mode of communication and problem solving. They also emphasized giving employees "responsible freedom” for solving emergent problems.

Follow-up on competence development. All of the development-oriented managers were keen to follow up on courses to ensure that the training was relevant and used in the work with the elderly. A common way of doing this was to ask employees to share and discuss what they had learned with their colleagues after they completed a certain course. They were also encouraged and, in many cases, coached in using the newly acquired knowledge and skills on the job:

We always follow up on training courses and tie the course content to the daily operations. I also make a plan together with the employees concerning how the training can be used. The employees grow when they know that they will be required to do something when they come back after training (DO2).

Thus, the development-oriented FLMs actively followed up on and supported employees’ learning as well as the application and use of the training on the job.

\subsubsection{Production-oriented mode of leadership}

Overall orientation. All of the production-oriented FLMs were characterized by a strong focus on administrative issues (e.g., reporting and budgeting) and a control of operations through business and operational plans. As emphasized by one FLM, it is important to

..... implement clear structures, functioning schedules and planning systems so that everyone knows what to do without discussion in order to ensure that the care recipients’ needs are met (PO3). 
Another important concern for many FLMs was to obtain good scores for their unit on different performance measures, such as economic results, quality or work environment, as measured by employee surveys:

I have, of course, a focus on the goals and results of the operations in order to get good scores on the quality indicators.... And, of course, also a focus on the budget and the economy of the unit (PO20). Many of the production-oriented FLMs experienced a heavy administrative workload, and they mainly worked in their offices, away from the daily operations. They described employee learning and competence development not as a priority in their work but rather as one of many responsibilities. Several of these managers also complained over difficulty in finding time to interact with employees and care recipients.

Learning orientation. A main concern among the production-oriented FLMs was to align the employees with the organization's goals and to create common routines for what applies in different situations and for how to handle and respond to the needs of care recipients:

It is important to lead the employees in the right direction towards an engaged and effective way of working. ...... and that there is no uncertainty among the employees about what applies in different situations (PO15).

If I notice something that is not correct, or not the best way of doing this or that, I will take up the matter and correct it immediately (PO20).

These and several other production-oriented managers seemed to prefer to use one-way communication and instructions to inform the employees about what applies in different matters. It is also clear from these quotations that the production-oriented managers tended to adopt a controlling attitude and to narrow the discretion of the staff. Taken together, these and other similar statements indicate an adaptive learning orientation.

Leading and organizing learning and competence development. The production-oriented FLMs viewed and handled employee learning and competence development as one of many administrative responsibilities that they were required to do: 
We are required by the formal agreement with the municipality to provide competence development for the employees, and this is, of course, something that we have to do (PO16).

Some of the FLMs also admitted that competence development might be one of the things that they "forget about", especially so if the staff's demand for competence development is low:

You easily forget about competence development given all other things that you also have to attend to. If nobody among the staff actively knocks on your door and asks for competence development, nothing will be done; that's the way it is (PO17).

Despite their ambivalence about engaging in employee learning and development issues, most of the production-oriented FLMs appeared to do what was required in that regard by formal agreements. Typically, the production-oriented FLMs relied on formal routines for handling the competence development of employees:

We have a competence development plan in our company that we are supposed to follow. .... My role is to find out the employees' interests for competence development and then try to match these interests with the needs of the unit (PO9).

In practice, their ways of understanding and handling learning issues were mainly restricted to formal education and training through different forms of courses, mostly web-based ones. The production-oriented managers expressed little or no focus on employee participation, reflection or learning in meetings and everyday work situations. Indeed, some of the FLMs argued that learning in everyday work was the responsibility of the employees themselves and not something that the manager could be expected to organize.

Following up on competence development. Most of the production-oriented FLMs did not attend to or follow up on the results of competence development activities for employees. As stated by two of the FLMs:

This is an improvement area; I usually don't follow up on competence development. I ought to set aside time for that on our staff meetings, but it is forgotten due to everything else that need to be dealt with (PO23). 
We don't follow up on the content of training and the extent that it is applied in daily operations, but we check if the employees have passed the test that is part of the course and thus is approved (PO9).

Thus, the above-quoted manager and several of the others perceived training follow-up as a matter of "ticking the box" and counting how many of the employees had completed a certain course.

Those FLMs who followed up on training did so by asking employees to tell their colleagues about the content of the course when they were back from training. However, some of these managers indicated that these events had become a sort of "ritual" in which neither managers nor employees were truly engaged. On these grounds, some of the managers also explicitly questioned the value of this kind of follow-up activity. Others expressed that it was employees’ own responsibility to use what they had learned in their jobs.

\subsection{To what extent was the FLMs' learning-oriented leadership related to individual and} organizational characteristics (RQ2)?

As is clear from Table 2 below, the differences between FLMs with respect to learningoriented leadership were not significantly related to gender, age or years of managerial experience. Their basic educational background - that is, whether they had a professional education (academic degree) in social work, nursing/paramedics, behavioural sciences or HRD/HRM - was also not significantly related to their mode of learning-oriented leadership. The only aspect of the FLMs' educational background that was significantly related $(\mathrm{p}<.05)$ to their mode of learning-oriented leadership was whether they had participated in further education and training in HRD/HRM, communication or leadership development. While half of the development-oriented FLMs (50 percent) had participated in such education and training, only two of the production-oriented managers (10 percent) had done so.

With regard to management responsibilities, contrary to what might be expected, neither the number of employees (span of control) nor the number of organizational units for which the FLMs were responsible was significantly related to differences in learning-oriented 
leadership. The ownership of the elderly care operations (public or private) was also not significantly related to the FLMs’ learning-oriented leadership.

Table 2. Comparisons between development-oriented and production-oriented FLMs with respect to individual and organizational characteristics

\begin{tabular}{|c|c|c|c|c|c|}
\hline \multirow[t]{2}{*}{ Characteristics: } & \multicolumn{2}{|c|}{$\begin{array}{l}\text { Development-oriented } \\
\text { FLMs }(\mathrm{n}=10)\end{array}$} & \multicolumn{2}{|c|}{$\begin{array}{l}\text { Production-oriented } \\
\text { FLMs }(n=20)\end{array}$} & \multirow[b]{2}{*}{ p-value } \\
\hline & $\mathrm{n}(\%)$ & $\mathrm{M}(\mathrm{Sd})$ & n (\%) & M (Sd) & \\
\hline \multicolumn{6}{|l|}{ Demographics and background } \\
\hline Gender, female & $10(100)$ & & $17(85)$ & & ns \\
\hline Age & & $48.2(7.3)$ & & $50.0(7.9)$ & ns \\
\hline Years of experience as a manager & & $12.7(10.7)$ & & $14.6(8.6)$ & ns \\
\hline \multicolumn{6}{|l|}{ Highest level of education } \\
\hline Academic degree in social work & $4(40)$ & & $10(50)$ & & ns \\
\hline $\begin{array}{l}\text { Academic degree in nursing or } \\
\text { paramedics }\end{array}$ & $2(20)$ & & $9(45)$ & & ns \\
\hline $\begin{array}{l}\text { Academic degree in behavioural } \\
\text { sciences or in } \mathrm{HRD} / \mathrm{M}\end{array}$ & $2(20)$ & & $1(5)$ & & ns \\
\hline Upper secondary school & $2(20)$ & & 0 & & ns \\
\hline \multicolumn{6}{|l|}{ Further education and training } \\
\hline $\begin{array}{l}\text { Courses in HRD/M, communication } \\
\text { or leadership development }\end{array}$ & $5(50)$ & & $2(10)$ & & $\mathrm{p}<.05$ \\
\hline \multicolumn{6}{|l|}{ Management responsibility } \\
\hline Number of employees <36 (Md) & $6(60)$ & & $9(45)$ & & \\
\hline Number of employees >36 (Md) & $4(40)$ & & $11(55)$ & & ns \\
\hline Responsibility for one unit & $4(40)$ & & $11(55)$ & & \\
\hline Responsibility for two or three units & $6(60)$ & & $9(45)$ & & ns \\
\hline \multicolumn{6}{|l|}{ Ownership of operations } \\
\hline Public/private & $4 / 6(40 / 60)$ & & $5 / 15(25 / 75)$ & & ns \\
\hline
\end{tabular}

\subsection{To what extent was the FLMs' learning-oriented leadership related to demands,} expectations or support from senior managers? (RQ 3)

The overall focus of the senior managers was to ensure that the FLMs ran their units in accordance with the formal agreement with the municipality and, specifically, that they did not exceed the budget framework:

I demand that they (the FLMs) run the operations in accordance with statutory rules and norms and the formal agreements with the municipality. We also demand, of course, that they do not exceed their budget framework (SM4). 
As is clear from the interviews, the senior managers devoted little or no focus on issues concerning employee learning and competence development, except that several mentioned in general terms that competence development is necessary “to deliver a good result”. However, they expressed few, if any, more specific expectations concerning how the FLMs should lead and organize the operations in their units. Additionally, none of them indicated that they specifically attended to, supported or followed up on the FLMs' work in relation to employee learning and competence development. Thus, in practice, the FLMs had a relatively high degree of autonomy concerning how to manage and lead the operations, and they were in many respects viewed as "small business owner-managers" with respect to how they ran their units:

I expect that I have managers that are independent ...... and that take the responsibility for what they do.... I don’t tell them what to do (SM6).

At the same time, however, the FLMs' discretion was constrained in several respects. Although they had the ultimate responsibility for daily operations, they were controlled by recurrent performance measurements in terms of budget, quality, and client and employee satisfaction. However, it seems safe to conclude that observed differences in the FLMs' learning-oriented leadership were not related to differences in demands, expectations or support from their senior managers.

\section{Discussion}

The purpose of this study was to explore what learning-oriented leadership could mean in practice and to identify possible sources of variability in this leadership between FLMs. The main findings are summarized and discussed below.

\subsection{Two modes of learning-oriented leadership}

This study contributes an in-depth analysis of two modes (patterns) of learning-oriented leadership: production-oriented and development-oriented (see Table 1). The two patterns represent a constraining and controlling versus an enabling and open mode of leading and 
organizing employee learning and competence development. The predominating, productionoriented mode of leadership - comprising two-thirds of the FLMs - was characterized by a focus on adaptive learning mainly through formal training and instructions. Learning and development were typically viewed as tasks with a low priority, and learning activities were carried out separately from meetings and daily work. As a consequence of this separating strategy, these managers reported a pressing need "to find time” for organizing and following up on learning and development activities, which they often failed to do.

The more infrequent, development-oriented mode - comprising one-third of the FLMs was characterized by a focus on promoting learning and reflection through a participatory and dialogue-oriented leadership. These managers were also able to integrate operational work and learning activities and thereby “create time” for working with learning and development issues. For example, the development-oriented FLMs used events in daily work or in meetings as opportunities for reflection and developmental learning concerning prevailing routines and ways of working. Thus, in many respects a development-oriented mode comes close to a coaching leadership (e.g. Hamlin et al., 2006; McCarthy \& Milner, 2013).

The predominance of a production-oriented mode of leadership is in line with observations in previous research concerning the reluctance of line managers to engage in a coaching leadership role (Ellinger et al., 2011), and also with the stability in the FLM role over time and across organizations as reported by Hales (2005; 2006/2007). Given that the leadership of FLMs has a key role in shaping the learning environment of a workplace (e.g. Fuller \& Unwin, 2004) - in this case workplaces within elderly care - a significant implication of our findings is that the predominance of a production-oriented leadership is likely to create workplaces with a constraining rather than an enabling learning environment (cf. Ellström, Ekholm \& Ellström, 2008), and thereby also with less than optimal conditions and opportunities for workplace learning. 


\subsection{Understanding differences in learning-oriented leadership}

Contrary to what could be expected from previous studies (see section 2.3), there were few differences in terms of organizational or individual characteristics between FLMs with a development-oriented and those with a production-oriented mode of leadership (see Table 2). More specifically, neither the managers' workload (i.e., number of employees/span of control and number of care units) nor the ownership of the care unit (public or private) was significantly related to differences in learning-oriented leadership.

Second, only one of the individual characteristics included in the analysis - whether FLMs had participated in further education and training in HRD/HRM, communication or leadership development - was significantly related to their mode of learning-oriented leadership (see Table 2). Participation in such further education and training is viewed here as an indicator (a proxy) of the FLMs' level of competence in understanding and handling employee learning and development and/or of their motivation for addressing these issues. This interpretation is supported by our finding that development-oriented FLMs also expressed greater interest in working with learning and development issues than productionoriented managers.

Third, we found no differences in demands, expectations or support between the senior managers that could explain the observed differences in learning-oriented leadership between the FLMs. Although the FLMs were constrained by economic goals and different performance measures, they simultaneously had a relatively high degree of discretion with respect to how they chose to carry out their work, particularly work related to employee learning and development.

Taken together, these findings are consistent with and can be understood in terms of the demands-constraints-choices model of managerial work proposed by Stewart (1982; 1989). According to this model, managers have considerable discretion - within certain constrains 
and demands - and constantly make choices in defining and performing their work. The managers' choices are often unconscious and based on subjective factors such as values, beliefs and agendas, among other things (Stewart, 1989). These choices are assumed to shape how they carry out their work, that is, what they do and how they do it.

This model and our findings are supported by a number of previous studies on line managers' work, which show that managers’ performance of HR tasks is more discretionary than their work with other, more traditional management duties (McGovern et al., 1997; Hutchington and Purcell, 2007; 2010) and that managers’ personal priorities, abilities (competence) and HR training play an important role for the extent to which they engage in HR tasks (Bos-Nehles et al., 2013; Carroll and Gillen, 2002; Hutchington and Purcell, 2007).

\subsection{Limitations}

The study has some limitations that need to be considered. First, the use of self-report data presents potential limitations related to the internal validity of the findings (e.g. discrepancies between what people say that they do and what they actually do). In particular, there has traditionally been a bias against using telephone interviews in qualitative research. As shown by Novick (2008), however, there is little evidence that the quality of findings is compromised through the use of telephone interviews. In fact, studies have reported a number of advantages of telephone interviewing over in-person interviewing, including that interviewees are likely more relaxed, more willing to talk freely and more likely to disclose sensitive information (Novick, 2008).

Nonetheless, to address the inherent limitations of interview data, we have continuously being mindful to explore alternative interpretations of the empirical material. Furthermore, data from the telephone interviews were followed up with a sub-sample of FLMs through shadowing (Czarniawska, 2007) and contextual, in-depth interviews. This methodological 
triangulation enabled us to validate data from the interviews and to obtain a richer and more detailed description and analysis of the FLMs’ work.

Second, considering the relatively small sample size, the findings need to be interpreted carefully - this is true in particular with respect to the quantitative analyses that were carried out to address the second research question. Third, because the study was based on a nonrandom sample of FLMs, the empirical generalizability of the results is limited. However, the fact that the main results are consistent with a number of previous studies arguably strengthens the analytic generalizability of the findings (Firestone, 1993).

\subsection{Implications for research and practice}

Drawing on the findings from the present study, there are at least three issues that need to be addressed by future research. First, to study the effects of the two modes of learning-oriented leadership on employees’ informal learning at work, and also on learning outcomes and transfer from formal training and development efforts. That is, to explore whether it actually matters in terms of employee learning if managers use a development-oriented or a production-oriented mode of leadership.

Second, to further pursue the issue why managers choose to engage in the one or the other mode of learning oriented leadership. Specifically, to explore the relative importance of individual and organizational (contextual) factors for explaining FLMs’ choices concerning how to practise a learning-oriented leadership. Third, to gain a deeper understanding of the integrative strategies that were used by the development-oriented managers to be able to work simultaneously with (or switch between) operational work and activities to facilitate employee learning.

As regards practical implications, two issues stand out as particularly important for organizations to deal with given the findings of this study. First, if organizations are serious in trying to meet the increasing demands for employee learning and competence development - 
beyond general rhetoric - learning and development issues should be clearly linked to business strategies. Furthermore, senior managers should actively attend to, support and follow up on the FLMs' work with employee learning and competence development, thereby taking an active ownership over these issues.

Second, there is a strong need for management training and development with a focus on improving line managers' knowledge of and skills in leading and organising workplace learning. However, equally or perhaps even more important is that there are support for informal learning concerning these issues in managers' everyday work. This could be organized for example as mentoring from peers, peer reviews or participation in professional learning communities or networks. Human resource departments potentially have an important task as strategic partners in organizing and follow-up on these arrangements.

\section{References}

Bos-Nehles, A. C., van Riemsdijk, M. J. and Looise, J. K. (2013), “Employee perceptions of line management performance: applying the AMO theory to explain the effectiveness of line managers’ HRM implementation”, Human Resource Management, Vol. 52 No. 6, pp. 861-877.

Carroll, S.J. and Gillen, D.J. (2002), "Exploring the teaching function in the managerial role”, Journal of Management Development, Vol. 21 No. 5, pp. 330-342.

Coetzer, A. (2007), “Employee perceptions of their workplaces as learning environments”, Journal of Workplace Learning, Vol. 19 No. 2, pp. 417-434.

Cunningham, I. and Hyman, L. (1999), “Devolving human resource responsibilities to the line”, Personnel Review, Vol. 28 No. 1/2, pp. 9-27.

Czarniawska, B. (2007), Shadowing and other techniques for doing fieldwork in modern societies, Liber AB, Malmö. 
Dirkx, J. M. (1999), “Invited Reaction: Managers as Facilitators of Learning in Learning Organizations”, Human Resource Development Quarterly, Vol. 10 No. 2, pp. 127-134.

Döös, M., Johansson, P. and Wilhelmson, L. (2015), “Beyond being present: learningoriented leadership in the daily work of middle managers”, Journal of Workplace Learning, Vol. 27 No. 6, pp. 408-425.

Ekholm, B. (2012), “Middle managers in elderly care under demands and expectations”, Leadership in Health Services, Vol. 25 No. 3, pp. 203-215.

Ellinger, A.D. (2005), “Contextual factors influencing informal learning in a workplace setting: The case of 'reinventing itself company' ”, Human Resource Development Quarterly, Vol. 16 No. 3, pp. 389-415.

Ellinger, A.D., Hamlin, R.G. and Beattie, R.S. (2008), “Behavioural indicators of ineffective managerial coaching. A cross-national study”, Journal of European Industrial Training, Vol. 32 No.4, pp. 240-257.

Ellinger, A. D., Hamlin, R. G., Beattie, R. S., Wang, Y. L. and McVicar, O. (2011), Managerial coaching as a workplace learning strategy. In: R.F. Poell and M. van Woerkom (Eds.) Supporting Workplace Learning. Dordrecht: Springer (pp. 71-87).

Ellinger, A.D., Watkins, K.E. and Barnas, C.M. (1999), ”Responding the new roles: A qualitative study of managers as instructors”, Management Learning, Vol. 30 No. 4, pp. 386-412.

Ellström, E. (2012), “Managerial support for learning at work: a qualitative study of first-line managers in elder care”, Leadership in Health Services, Vol. 25 No. 4, pp. 273-287.

Ellström, E., Ekholm, B. and Ellström, P.-E. (2008), “Two types of learning environment: Enabling and constraining. A study of care work”, Journal of Workplace Learning, Vol. 20 No. 2, pp. 84-97. 
Ellström, P.-E. (2001), “Integrating learning and work: Problems and prospects”, Human Resource Development Quarterly, Vol. 12 No. 4, pp. 421-435.

Ellström, P.-E. (2006), “Two logics of learning”, in Antonacopoulou, E.P. et al. (Eds) Learning, working and living. Mapping the terrain of working life learning, Palgrave Macmillan, New York.

Ellström, P.-E. (2010), “Practice-based innovation: a learning perspective”, Journal of Workplace Learning, Vol. 22 No. 1/2, pp.27-40.

Ellström, P.-E. (2011). Informal Learning at Work: Conditions, Processes and Logics. In: M. Malloch, M.L. Cairns, K. Evans and B. N. O’Connor (Eds), The SAGE Handbook of Workplace Learning. Thousand Oaks, CA, Sage Publications Inc., pp. 105-119.

Firestone, W. A. (1993), “Alternative arguments for generalizing from data as applied to qualitative research”, Educational Researcher, Vol. 22 No. 4, pp. 16-23.

Fuller, A and Unwin, L. (2004), “Expansive learning environments: integrating organizational and personal development”, in Rainbird, H et al. (Eds), Workplace learning in context, Routledge, London.

Furåker, C and Nilsson, A. (2010), “Age care managers in residential facilities - aspects of competence”, Leadership in Health Services, Vol. 23 No. 1, pp. 33-45.

Hales, C.P. (2005), “Rooted in Supervision, Branching into Management: Continuity and Change in the Role of First-Line Manager”, Journal of Management Studies, Vol. 42 No. 3, pp. 471-506.

Hales, C. (2006/2007), “Moving down the line? The shifting boundary between middle and first-line management”, Journal of General Management, Vol. 32 No. 2, pp. 31-55.

Hamlin, R. G., Ellinger, A. D. and Beattie, R. S. (2006), “Coaching at the Heart of Managerial Effectiveness: A Cross-Cultural Study of Managerial Behaviours”, Human Resource Development International, Vol. 9 No. 3, pp. 305-331. 
Hasson, H. and Arnetz, J. E. (2008), "Nursing staff competence, work strain and satisfaction in elderly care: a comparison of home based care and nursing homes”, Journal of Clinical Nursing, Vol. 17 No.4, pp. 468-481.

Hutchinson, S. and Purcell, J. (2007), Learning and the Line: The role of Line Managers in Training, Learning and Development, CIPD Publishing, London.

Hutchinson, S. and Purcell, J. (2010), "Managing ward managers for roles in HRM in the NHS: Overworked and under-resourced”, Human Resource Management Journal, Vol. 20 No. 4, pp. 357-374.

Layder, D. (1998), Sociological Practice. Linking Theory and Social Research. London, Sage Publications.

Malloch, M., Cairns, L., Evans, K. and O’Connor, B.N. (Eds) (2011), The SAGE handbook of workplace learning, Sage, London.

March, J. G. (1991), “Exploration and exploitation in organizational learning”, Organization Science, Vol. 2 No.1, pp. 71-87.

McCarthy, G. and Milner, J. (2013), “Managerial coaching: challenges, opportunities and training”, Journal of Management Development, Vol. 32 No. 7, pp. 768-779.

McGill, M. E., Slocum, J. W. and Lei, D. (1992), “Management practices in learning organizations”, Organizational Dynamics, Vol. 21 No. 1, pp. 5-17.

McGovern, P., Gratton, L., Hope Hailey, V., Stiles, P. and Truss, C. (1997), “Human resource management on the line?”, Human Resource Management Journal, Vol. 7 No. 4, pp. 1229.

Miles, M. B. and Huberman, A. M. (1994), Qualitative Data Analysis. An Expanded Sourcebook, Sage Publications, Thousand Oaks, CA.

Mintzberg, H. (2009), Managing, San Francisco, CA, Berrett-Koehler Publishers Inc. Novick, G. (2008), “Is There a Bias Against Telephone Interviews in Qualitative Research?” 
Research in Nursing and Health, Vol. 31 No. 4, pp. 391-398.

Patton, M. Q. (1990), Qualitative Evaluation and Research Methods. 2nd ed. Newbury park, CA, Sage.

Poell, R. F. and van Woerkom, M. (Eds) (2011), Supporting Workplace Learning. Towards Evidence-Based Practice, Springer, Dordrecht.

Stewart, R. (1982), Choices for the Manager, Englewood Cliffs, NJ, Prentice Hall.

Stewart, R. (1989), “Studies of managerial jobs and behaviour: The ways forward”, Journal of Management Studies, Vol. 26 No. 1, pp. 1-10.

Tashakkori, A. and Teddlie, C. (Eds) (2003), Handbook of Mixed Methods in Social and Behavioral Research, Sage Publications, Thousand Oaks, CA.

The National Board of Health and Welfare (2011), National Leadership Development for Managers within Elderly Care, Socialstyrelsen, Stockholm.

Wallo, A. (2008), The leader as facilitator of learning at work. A study of learning-oriented leadership in two industrial firms, dissertation, Linköping Studies in Behavioural Sciences No.137, Linköping University Linköping.

Wallo, A. (2017). Learning-Oriented Leadership: managers as facilitators of Human Resource Development in daily Work. International Journal of HRD Practice, Policy and Research. Vol. 2 No. 1, pp. 21-34.

Wallo, A., Ellström, P.-E. and Kock, H. (2013). Leadership as a balancing act between performance and development-orientation: a study of managers’ and co-workers’ understanding of leadership in an industrial organization. Leadership and Organizational Development Journal, Vol. 34 No. 3, pp. 222-237.

Whittaker, S. and Marchington, M. (2003), “Devolving HR responsibility to the line: threat, opportunity or partnership”, Employee Relations, Vol. 25 No. 3, pp. 245-261. 
Viitala, R. (2004), “Towards knowledge leadership”, Leadership and Organization Development Journal, Vol. 25 No. 6, pp. 528-44.

Yukl, G. (2009), “Leading organizational learning: Reflections on theory and research”, The Leadership Quarterly, Vol. 20 No. 1, pp. 49-53.

Yukl, G. (2013), Leadership in Organizations, $8^{\text {th }}$ Edition, Upper Saddle River, NJ, PrenticeHall International Inc. 